process, which they considered to be automatic and inaccurate. Actually, both geocoding processes are subject to uncertainties and inaccuracies. The coordinates based on photographs may also be inaccurate and may even overestimate the distance, for instance, by locating dwellings in the middle of the building instead of by the roadside. Moreover, the main geocoding was also completed manually, particularly for rural areas, and was not merely automatic. While the main geocoding was accessible for the entire sample, the photographic views were available for a subset of addresses, most often in urban areas, and unequally for the cases and controls. Overall, the sensitivity analyses did not call into question the conclusions of the main analyses and for that reason were not reported in the abstract.

Bonnet-Belfais et al (2013) listed some differences between the main analyses and the sensitivity analyses, and mistakenly interpreted them as if the photographs yielded the true coordinates. We performed sensitivity analyses to assess the robustness of the results under different uncertainty scenarios, and therefore restricted the analyses to the addresses the most precisely located by the main geocoding process or to the addresses geocoded with a photographic view (Table 5). We also used other limits of distance $(30,40,60$ and $70 \mathrm{~m})$ from the lines. All of the sensitivity analysis results supported the main results, sometimes smoothing and sometimes strengthening them. It is also to be noted that our study did not include any assessment of MF exposure that could be used to refute or confirm 'distance as an inappropriate MF exposure surrogate'. Bonnet-Belfais et al (2013) express their belief that 'personal exposure (is) the only one (MF exposure surrogate) relevant in terms of public health.' This belief is debatable in the absence of any established causal link with MF. It is noteworthy that measurements of personal exposures are difficult to standardise and subject to selection and measurement errors, particularly in the context of case-control studies, in which the exposures are usually available for a limited timeframe, and for a selected and sometime small fraction of the study samples. This may weaken the relevance of those exposures in terms of public health.

The next stages of our study will include a case-by-case model-based assessment of exposure to ELF-MF. The assessment should enable further elucidation of the exposures or biases underlying our findings and the other environmental factors that may be associated or co-associated with power lines and/or ELF-MF exposure.

\section{REFERENCE}

Bonnet-Belfais M, Lambrozo J, Aurengo A (2013) Comment on 'Childhood leukemia close to high-voltage power lines - the Geocap study, 2002-2007' - Is proximity an appropriate MF exposure surrogate? Br J Cancer 109(5): $1382-1383$.

cc)(i)(2) This work is licensed under the Creative Commons Attribution-NonCommercial-Share Alike 3.0 Unported License. To view a copy of this license, visit http://creativecommons. org/licenses/by-nc-sa/3.0/

\title{
Comment on 'Childhood leukaemia close to high-voltage power lines - the Geocap study, 2002-2007' - Odds ratio and confidence interval
}

\author{
M T Magaña Torres ${ }^{1}$ and J R Gonzalez Garcia ${ }^{\star, 1}$ \\ ${ }^{1}$ Division de Genetica, Centro de Investigacion Biomedica de Occidente, Instituto Mexicano del Seguro Social, \\ Sierra Mojada \#800, Colonia Independencia, Guadalajara, Jalisco CP 44340, Mexico
}

Sir,

The precision of the odds ratio (OR) test is estimated by the $95 \%$ confidence interval, which is interpreted as significant when its values do not overlap the 1.0 null value (Szumilas, 2010). In this context, some sentences of the results section in the paper by Sermage-Faure et al (2013) are unwarranted. These sentences are 'an association was evidenced for children who lived within $50 \mathrm{~m}$ of a VHV-HVOL $(\mathrm{OR}=1.7(0.9-3.6))$ '; 'The results for ALL were 
very similar $(\mathrm{OR}=1.9(0.9-4.0)$ at $<50 \mathrm{~m}$ from a VHV-HVOL)'; 'In that age group, living within $50 \mathrm{~m}$ of the closest VHV-HVOL was significantly associated with $\mathrm{AL}(\mathrm{OR}=2.6(1.0-7.0))$ '; and 'Sensitivity analyses restricted to the best geocoded subjects (uncertainty $\leqslant 20 \mathrm{~m}$ ) generated slightly stronger results $(\mathrm{OR}=2.1(0.9-4.7)$ for living within $50 \mathrm{~m}$ of a VHV-HVOL)'. Inasmuch as all these confidence intervals intersect the 1.0 null value, they must not be interpreted as significant ones. Therefore, the conclusion that 'living $<50 \mathrm{~m}$ from a 225 or $400 \mathrm{kV}$ HVOL may be associated with an increased incidence of childhood AL' is biased by this statistical concern. This situation contains a strong potential to generate confusion, distorts the knowledge, and hampers the understanding of the acute leukaemia aetiology.

\section{REFERENCES}

Sermage-Faure C, Demoury C, Rudant J, Goujon-Bellec S, Guyot-Goubin A, Deschamps F, Hemon D, Clavel J (2013) Childhood leukaemia close to highvoltage power lines - the Geocap study, 2002-2007. Br J Cancer 108: 1899-1906. Szumilas M (2010) Explaining odds ratios. J Can Acad Child Adolesc Psychiatry 19: 227-229.

(c) (i) (2) (2) This work is licensed under the Creative Commons (c) Attribution-NonCommercial-Share Alike 3.0 Unported License. To view a copy of this license, visit http://creativecommons. org/licenses/by-nc-sa/3.0/

\title{
Reply: Comment on 'Childhood leukaemia close to high-voltage power lines - the Geocap study, 2002-2007' - Odds ratio and confidence interval
}

\author{
J Clavel ${ }^{\star, 1,2,3}$ and D Hémon ${ }^{1,2}$ \\ ${ }^{1}$ Inserm U1018, Center for Research in Epidemiology and Population Health (CESP) Equipe 6, Environmental Epidemiology of \\ Cancer Team, 16 Av. Paul Vaillant-Couturier, F-94807 Villejuif, France; ${ }^{2}$ University Paris-Sud, UMRS 1018, F-94807 Villejuif, France \\ and ${ }^{3}$ French National Registry of Childhood Hematological Malignancies (NRCH), Villejuif, France
}

Sir,

Magaña Torres and Gonzalez Garcia (2013) expressed their concern about what they call 'a strong potential (of our conclusions) to generate confusion'. However, we provided the reader all the keys to understand our results and make proper statistical inferences. We reported the details of our analyses, the estimates and their 95\% confidence intervals (CIs), the results of the sensitivity analyses, and our own conclusions were factual. The question we formulated was one-sided ('Is there an increase in childhood AL risk close to HVOL?'), and we let the readers decide whether two-sided tests should be the most relevant for statistical inference, and whether the 95\% CIs should be used for this purpose. In the specific phrases emphasised, we basically commented on the main figures: OR of $1.7(0.9-3.6)$ and 1.9 (0.9-4.0) are close, $2.6(1.0-7.0)$ is a significant association at the 0.05 level of significance (two-sided), 2.1 is slightly higher than 1.7. We think that Magaña Torres and Gonzalez Garcia (2013) overvalue the CIs by using them for decision rules while they are given to quantify the precision of the ORs, whatever the power of the study, the number of tests, the weight of the literature that may influence the actual tests. Given the results, our statement 'In conclusion, the present study has generated additional findings, based on a recent nationwide unselected population-based study, that support the hypothesis that living $<50 \mathrm{~m}$ from a 225 or $400 \mathrm{kV}$ HVOL may be associated with an increased incidence of childhood AL' seems a balanced conclusion.

\section{REFERENCE}

Magaña Torres MT, Gonzalez Garcia JR (2013) Comment on 'Childhood leukaemia close to high-voltage power lines - the Geocap study, 2002-2007' - Odds ratio and confidence interval. Br J Cancer; 109(5): 1384-1385.

(c) (i) (2) This work is licensed under the Creative Commons (c) ${ }_{\text {BY }}$ NG SA Attribution-NonCommercial-Share Alike 3.0 Unported License. To view a copy of this license, visit http://creativecommons. org/licenses/by-nc-sa/3.0/ 